\title{
OS NOVOS ENFOQUES DA GEOGRAFIA COM O APOIO DAS TECNOLOGIAS DA INFORMAÇÃO GEOGRÁFICA
}

\author{
Reinaldo Paul Pérez Machado ${ }^{1}$
}

Resumo: Tratou-se neste artigo de relevar o papel da Cartografia e das formas de analisar $e$ representar o espaço, através de métodos qualitativos e quantitativos. Foram consideradas, em especial, as novas tendências e desafios das Tecnologias da Informação Geográfica, diante dos principais paradigmas que estão em foco no debate atual na Geografia. A partir do trabalho de Kuhn, em 1970, muitos geógrafos e estudiosos da evolução do pensamento geográfico aplicaram o modelo da mudança de paradigmas ao desenvolvimento conceitual desta ciência. No entanto, analisando a evolução da Geografia do século XX e início do XXI, tem-se observado certa regularidade de mudanças paradigmáticas entre os chamados "períodos de desenvolvimento da ciência normal", com ciclos de duração entre 20 e 25 anos (Buzai, 1999). Mas também se verificou que em nenhum momento um paradigma eliminava por completo o anterior, mas o deslocava no tempo. Assim vemos o atual ressurgimento da Geografia Quantitativa, com uma quantidade expressiva de trabalhos e novas propostas de cálculo, análise e modelagem temática complexa, derivadas do impacto que têm exercido as tecnologias da informação neste campo, o que há dado lugar às denominadas Tecnologias da Informação Geográfica, ou Geotecnologias. No entanto, também se percebe a presencia ativa do chamado Paradigma Humanista, mediante o qual se tem construído uma visão espacial alternativa e independente, seguindo certos fundamentos iniciais, a partir dos estudos culturais de vertentes geográfico-antropológicas (Sauer, 1925, 1927, 1963), e daqueles outros relacionados com os mapas mentais urbanos (Cauvin, 2002; Strauss, 1987; Lynch, 1960). Aqui, a Geografia Humana centra seu foco na relação do mundo interior com o mundo exterior do ser humano, tais como a percepção, as atitudes e a valoração do meio geográfico. Neste sentido, foram analisados diferentes exemplos de aplicações dos SIG diante de uma série de problemáticas territoriais cujos propósitos, estratégias de investigação e conhecimento obtidos se agrupam dentro do reforço do paradigma quantitativo e também na construção de modelos qualitativos, mapas mentais, participativos e colaborativos, dentro do Paradigma Humanista. Estas aplicações mostraram, em geral, opções de soluções aplicadas, com base no desenvolvimento tecnológico e na Geografia atual, como disciplina central. Embora os Sistemas de Informação Geográfica, isoladamente, não sejam considerados como parte da Ciência da Informação Geográfica (Capel, 2005), o desenvolvimento recente (e crescente) das Tecnologias da Informação Geográfica indica que sim, está acontecendo uma mudança paradigmática, que levará, através do estabelecimento de fundamentos teóricos, conceituais e ontológicos profundos, à consolidação da Ciência da Informação Geográfica. O desenvolvimento deste processo beneficiará incontestavelmente, todas as expressões do conhecimento geográfico, independentemente de ter ênfase maior nos aspectos físicos ou humanos.

\footnotetext{
${ }^{1}$ Possui graduação em Geografia - Universidad de La Habana (1981), pós-graduação no International Institute for Aerospace Survey and Earth Sciences ITC da Holanda (1990), doutorado em Ciências (Geografia Humana) pela Universidade de São Paulo (2001) e Livre Docência pela Universidade de São Paulo (2012). Realizou pós-doutorado na Universitat de Barcelona (2006-2007), e no Center for International Earth Science Information Network CIESIN da Universidade de Columbia, em Nova Iorque (2009). É professor da Universidade de São Paulo na graduação e na pós-graduação do Departamento de Geografia desde 1994. Participante como Professor Convidado do Programa Erasmus Mundus na Faculty of Geoinformation Science and Earth Observation ITC da University of Twente em Holanda, e na University of Lund, de Suécia (2010). Presidente da Comissão Organizadora e do Comitê Científico do II Simpósio Internacional Caminhos Atuais da Cartografia na Geografia 2ㅇ CARTOGEO, celebrado no DG - USP (2010). Tem experiência na área de Cartografia, com ênfase em Geografia Urbana, atuando principalmente nos seguintes temas: geoprocessamento, sistemas de informações geográficas, análise espacial, sensoriamento remoto e as aplicações das Tecnologias da Informação Geográfica nos temas sociais.
} 
Palavras chave: Geografia Quantitativa; Geografia Qualitativa; Geografia Humana; Ciência da Informação Geográfica; Cartografia Digital; Mapas Mentais.

\section{Os Sistemas de Informação Geográfica (SIG) e a revalorização do paradigma quantitativo} na Geografia.

A partir da publicação do trabalho de Thomas Samuel Kuhn, The Structure of the Scientific Revolutions (Kuhn, 1970), muitos geógrafos estudiosos da evolução do pensamento geográfico aplicaram o modelo da mudança de paradigmas ao desenvolvimento conceitual dessa ciência. Porém, analisando a evolução da Geografia do Século XX e inicio do século atual, é possível observar certa regularidade nas mudanças paradigmáticas entre os chamados "períodos de desenvolvimento da ciência normal", com tempos de duração entre 20 e 25 anos (Buzai, 1999). Também se tem verificado que um paradigma não eliminava totalmente o anterior; na verdade, o deslocava, momentaneamente, da tendência principal e, inclusive, o mesmo poderia exibir um posterior fortalecimento e expansão, uma espécie de regeneração em períodos seguintes.

Desta maneira, como a Geografia Quantitativa não eliminou a Geografia Regional, nem a Geografia Racionalista, da mesma forma, os paradigmas da Geografia Crítica - também em plena retomada (Carlos, 2007) - e da Geografia Humanista, não eliminaram o paradigma quantitativo dos anos 50 e 70. É assim como Slocum (1990) demonstra que a perspectiva quantitativa aumentou sua produção de trabalhos e se ampliaram suas possibilidades metodológicas, com o desenvolvimento das Tecnologias da Informação Geográfica, a partir da década de 1980.

Este impulso tecnológico representa uma revitalização do paradigma quantitativo. Em primeiro lugar, recupera-se, como objeto de estudo central, o espaço geográfico e, junto com a ele, a diferenciação de áreas como marco da ciência aplicada. Os fenômenos e processos, assim como as entidades ou feições localizadas sobre a superfície terrestre, dificilmente poderiam ser reivindicados como objetos exclusivos de estudo de disciplinas particulares. Portanto, a questão central de cada campo do conhecimento é seu enfoque, e o enfoque geográfico sob esta abordagem revela-se de forma claramente espacial e, neste sentido, as teorias e metodologias da Geografia estão destinadas ao estudo das localizações, distribuições, associações, internalizações e evoluções espaciais. Nas atuais circunstâncias os geógrafos, mais do que quaisquer outros profissionais, são "espaciólogos", como definiu Milton Santos (Por uma Geografia Nova, 2002). 
Dobson (1993) reconhece que a atual revalorização da Geografia Quantitativa tem sido abordada, principalmente, no seu caráter de revolução tecnológica e não como verdadeira revolução científica. No entanto, não se duvida de um impacto amplo na disciplina, com ganhos que trasladam a Geografia como ciência até novos limites e, neste sentido, se há começado a dar maior sustento (e atenção) à base teórica da tecnologia, desde uma visão centrada nos sistemas de informações com o componente geográfico (Ferreira, 2006). Lentamente se começa a considerar que os SIG, como tecnologia, podem aproveitar-se, em sua verdadeira potencialidade, e seus resultados serem corretamente interpretados, se maior atenção for dada aos conceitos geográficos, nos quais eles se baseiam (ibidem).

Assim vemos o atual ressurgimento da Geografia Quantitativa com uma impressionante quantidade de trabalhos e inovadoras propostas metodológicas de cálculo, análise e modelação temática complexa, derivadas do impacto que têm exercido as tecnologias da informação neste campo e que têm dado lugar à denominada Geotecnologia da Informação, ou, mais especificamente, às Tecnologias da Informação Geográfica (Pérez Machado, 2009). Neste sentido, apresentam-se diferentes exemplos de aplicações dos Sistemas de Informações Geográficas diante de uma série de problemáticas territoriais cujos propósitos, estratégias de investigação e conhecimentos obtidos abrigam-se na revitalização do paradigma quantitativo e na construção de modelos qualitativos, mapas mentais, participativos e colaborativos, dentro do Paradigma Humanista. Estes produtos mostram, em geral, opções de soluções aplicadas baseadas no desenvolvimento tecnológico e na Geografia atual, como disciplina central. Por este motivo, manifestamo-nos contra as separações, facções ou compartimentações dentro da ciência que nos ocupa, pois, em nossa apreciação, praticamos Geografia em sua totalidade epistemológica e filosófica.

\section{O lugar da Geografia Quantitativa}

No artigo "Wittgenstein y la Geografía Cuantitativa Contemporánea" (Tapiador, 2004), este pesquisador analisa, profundamente, as decorrências do pensamento de Ludwig Wittgenstein, especialmente após sua recente releitura por Michael Luntley (2003), que oferece uma novidade sobre a visão tradicional sobre os escritos do renomado filósofo Vienés. Segundo Tapiador (2004), esta nova interpretação apresenta implicações tanto para as ciências sociais como para a Geografia. Algumas destas podem ser invocadas para situar a Geografia Quantitativa em seu 
contexto epistemológico, mostrando uma serie de elementos de interesse geográfico que podem servir para esclarecer o lugar da geografia quantitativa na geografia, ao mesmo tempo elucidando alguns aspectos da tarefa e âmbito da geografia em geral.

Assim, no seu artigo, Tapiador (ibidem) descreve como a intencionalidade, como fonte de gramática, é crucial para derivar consequências epistemológicas nas Ciências Sociais, em geral, e na Geografia, em particular. A posição de Wittgenstein sobre a intencionalidade é clara: a observação é posterior à gramática, ou seja, posterior à expressão do conjunto de regras que permite a interpretação das variáveis, e sua posterior análise. Assim, o que é observado depende de um marco teórico de referência, que deve ser estabelecido a priori. Embora, aparentemente, o interesse de Wittgenstein não fosse a criação de uma epistemologia, a partir de suas observações é possível derivar uma consequência epistemológica imediata aplicável à geografia: por trás de cada investigação geográfica existe uma ordem voluntária anterior, uma maneira de observar a realidade, que não pode ser estabelecida através da práxis desse sistema, mas sim que a precede. Conforme seja esse marco, será apresentada uma maneira ou outra de entender o conhecimento e a prática geográficos; maneiras estas que, longe de se opor entre si, e dado seu caráter "apriorístico" e intencional, decorrem, paralelamente, em sua construção da geografia, sem que seja, portanto, necessário estabelecer nenhum tipo de oposição entre elas, por mais que seus pressupostos sejam diferentes, como o que sucede, por exemplo, entre a prática da Geografia Física e a Geografia Humana.

Analisada desde esta lógica (prossegue o raciocínio de Tapiador), o interesse do geógrafo quantitativo não seria a procura da verdade geográfica, mas a análise do jogo linguístico (formalizado matematicamente) que descreve o mundo desde a postura apriorística, que o concebe, segundo um esquema objetivo formal. Esse jogo, expressado na terminologia de Wittgenstein, é o que se denomina análise geográfica, e cuja estrutura interna estaria pré-definida pela vontade do agente de dotar com sentido em chave "matematizável" os problemas geográficos. Refere-se ao jogo da postura objetiva com formalização lógica, o qual, por outro lado, implicaria numa vontade de explicar os problemas segundo o uso corrente da linguagem que utilizamos para nos comunicar, o que permitiria, neste caso, transladar ditos problemas ao público em geral. Isto seria um aspecto que prejudicaria o enfoque quantitativo, no caso deste ser analisado a partir de um posicionamento qualitativo.

Como conclusão, Tapiador (ibidem) afirma que a maior parte do trabalho de Wittgenstein consiste em um intento de estabelecer uma gnosiologia da epistemologia, mais do que resolver problemas 
concretos, embora seus logros intelectuais possam servir para elucidar problemas geográficos e posicionar as práticas geográficas em seus contextos epistemológicos.

\section{Os novos paradigmas.}

Poder-se-ia considerar que a Geografia Automatizada é um novo paradigma da Geografia. Sua aparição aconteceu 20-25 anos mais tarde que as últimas visões paradigmáticas já estabelecidas (Buzai, 1999), mas esta automatização, em nosso entender, não seria uma nova forma de ver a realidade, simplesmente significa que, mediante o uso das tecnologias digitais, foi possível automatizar muitos dos procedimentos de análise geográfica, realizados pela abordagem racionalista e quantitativa (Candeau Dufat, 2009, pág. 252). Por esse motivo consideramos que esta é uma excelente revalorização dessas posturas, através de um novo ambiente de trabalho.

Embora os Sistemas de Informações Geográficas, isoladamente, não são considerados como Ciência da Informação Geográfica (Capel, 2005), a presença e desenvolvimento recente (e crescente) das Tecnologias da Informação Geográfica indicam que sim, de fato, está acontecendo uma mudança paradigmática que levará, através do estabelecimento de fundamentos teóricos, conceituais e ontológicos profundos, à consolidação da Ciência da Informação Geográfica. O desenvolvimento deste processo beneficiará, muito provavelmente, todas as expressões do conhecimento geográfico, independentemente de ter uma ênfase maior nos aspectos físicos ou humanos (Pérez Machado, 2009).

Apenas como exemplo, poder-se-ia considerar a quantidade de trabalhos científicos apresentados por seções temáticas na XI Conferencia Iberoamericana de Sistemas de Información Geográfica (CONFIBSIG), celebrada em Buenos Aires, em maio de 2007. Chama a atenção que a seção SIG População e Qualidade de Vida foi a que, disparadamente, teve maior número de trabalhos, seguida por SIG e Saúde e depois Problemas Ambientais e Riscos Naturais. Ou seja, observa-se que a maioria (56\%) dos trabalhos apresentados no evento pode ser classificada dentro de temas relacionados com a Geografia Humana. Por outra parte, ao analisar a questão dos enfoques e orientação metodológica (ver Quadro 1) aprecia-se, claramente, uma utilização privilegiada dos aspectos tecnológicos. Simplesmente há omissão das aplicações dos Sistemas de Informação Geográfica aos novos campos emergentes da geografia e aos paradigmas da cartografia moderna. 
Quadro 1. Apresenta os enfoques e orientação metodológica dos trabalhos apresentados na $X I$ Conferencia Iberoamericana de Sistemas de Información Geográfica (CONFIBSIG) (Adaptado de Candeau e Pérez Machado, 2008).

\begin{tabular}{|c|c|}
\hline TRABALHOS & ENFOQUE E ORIENTAÇÃO METODOLÓGICA \\
\hline $90 \%$ & Resolver problemas reais dos territórios ibero-americanos \\
\hline $8 \%$ & Desenvolvimento de bases de dados espaciais e suas infra-estruturas (IDE) ${ }^{2}$ \\
\hline $2 \%$ & Outros temas \\
\hline $0 \%$ & Aplicação dos SIG aos novos campos emergentes da Geografia \\
\hline
\end{tabular}

A despeito das inovações que resultam, desde o ponto de vista da disciplina, as saídas cartográficas automatizadas destes trabalhos foram claramente conservadoras, mesmo considerando que se originaram num ambiente SIG. Efetivamente, a maioria das apresentações utilizava a ponderação dos aspectos metodológicos de análise e das tecnologias utilizadas, mais do que os significados geográficos dos resultados expressados cartograficamente. Em poucos casos, observou-se a inter-relação de processos e fenômenos naturais, ambientais e sociais por meio de mapas temáticos analíticos de fatores ou de causa/efeito. Mapas que utilizam os métodos complexos de representação cartográfica - sobretudo os cartodiagramas de diferentes desenhos (além do tradicional sectograma circular), sobreposto a cartogramas ou ao fundo qualitativo para comunicar os origens e fatores que intervêm no comportamento desses processos. Adicionalmente, é necessário destacar que, embora houvesse no evento uma preponderância de trabalhos de cunho social, verificou-se a ausência de trabalhos que combinassem indicadores sociais com fenômenos naturais, para produzir novos indicadores, como por exemplo, de qualidade de vida (Morato, Kawakubo, \& Luchiari, 2003), ou a desigualdade ambiental (Morato, 2008).

Esta pesquisadora combinou, com sucesso, diversas variáveis físico-geográficas, tanto quantitativas como qualitativas, e ainda dicotômicas (de presença/ausência) para obter um índice de qualidade ambiental, como se pode observar à Figura 1. Um aspecto relevante do trabalho foi o emprego de técnicas de Sensoriamento Remoto, como o Normalized Difference Vegetation Index

\footnotetext{
2 Infra-estrutura de Dados Espaciais - IDE pode ser definida como "o conjunto de esforços para garantir bases para descoberta, avaliação e utilização de dados espaciais", segundo a organização internacional Global Spatial Data Infrastructure (GSDI).
} 
$\overline{(N D V I)^{3}}$. Sua geração se dá pela diferença entre a reflectância do infravermelho próximo (IVP) e a reflectância do vermelho (V), dividida, respectivamente, pela soma das duas reflectâncias (TOWNSHEND apud SOUZA, 2010). A equação resulta em um índice que varia de -1 a 1 . (quanto maior o valor do índice, maior a presença de vegetação). Então, pode-se afirmar que o NDVI é a razão simples da diferença normalizada entre comprimentos de onda onde a vegetação possui alta reflectância da radiação solar (IVP) e um comprimento de onda onde ela possui baixa reflectância (V).

\section{Fórmula: NDVI = (IVP - V) / (IVP + V)}

\footnotetext{
${ }^{3}$ O NDVI (Normalized Difference Vegetation Index) ou IVDN (Índice de Vegetação por Diferença Normalizada) permite ressaltar o comportamento espectral da cobertura vegetal em relação ao solo e a outros alvos da superfície terrestre (realça o contraste espectral entre a vegetação e o entorno).
} 


\section{MAPA DA DESIGUALDADE AMBIENTAL DO MUNICÍPIO DE SÃO PAULO}

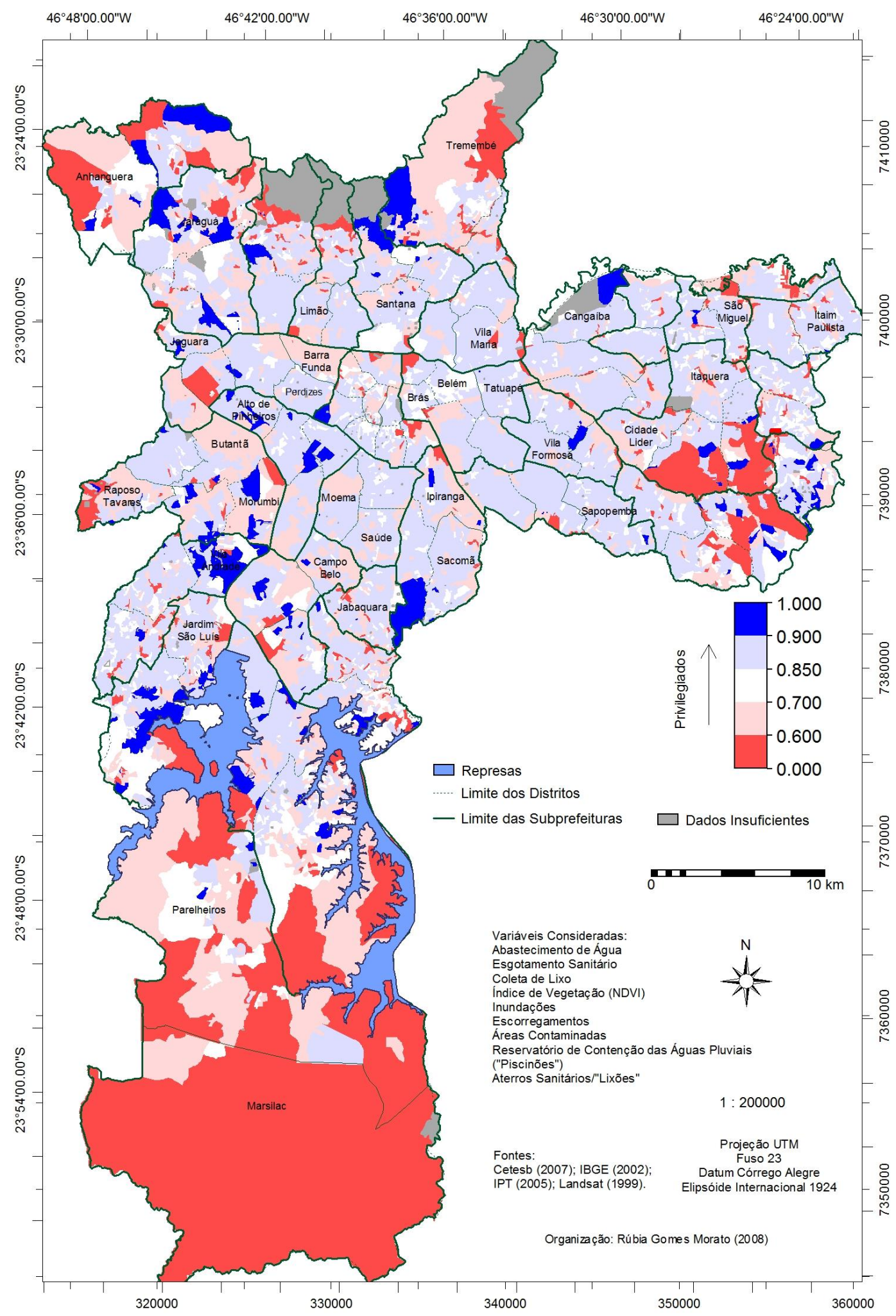

Figura 1. Mapa da Desigualdade Ambiental no Município de São Paulo. Nove variáveis foram combinadas para formar o índice que expressa a qualidade ambiental. Fonte: Tese de doutorado em Geografia Humana (Morato, Análise espacial e desigualdade ambiental no Município de São Paulo, 2008, p. 72). 
Atualmente se hão incorporado outros modernos paradigmas à Cartografia que marcam as novas funções que se atribuem aos mapas, a partir de sua confecção e uso nos meios computacionais (Candeau Dufat, 2009, pág. 256). Estes são:

$\checkmark$ Visualização. Implica o uso das técnicas gráficas para visualizar os objetos de forma tal que estes sejam mostrados da maneira mais realista possível. Ou seja, utilizando recursos visuais de volume (terceira dimensão), com texturas, que realcem a diversidade, e apresentados com apoio de fotografias aéreas, imagens satelitais e vídeos.

$\checkmark$ Conexão com a informação digital disponível. Indica que os elementos ou feições gráficas do mapa contem com uma ligação a outra informação gráfica ou alfanumérica não contida nele. Vale dizer, que se vinculem ao acervo digital disponível para sua consulta e análise nas bases de dados e nos endereços da WEB, em ambiente Intranet/Internet. Isto significa que já não é suficiente o desenho cartográfico do mapa, mas também que, adicionalmente, se faz necessário incorporar os hiper-vínculos de seus elementos a outros dados ou informações digitais externos para sua consulta.

$\checkmark$ Distribuição. Diz respeito ao impacto produzido pela Internet (world wide web), já que esta tem gerado a possibilidade de que os arquivos cartográficos possam estar disponíveis para sua consulta, análise, impressão e outras funções executadas por esta via sem necessidade de contar com a licença de software especializado. Tem-se visto que tampouco é suficiente dar por terminado o trabalho no formato proprietário do programa computacional, ou nas impressões analógicas em papel, ainda é necessário migrá-lo a este novo ambiente, para garantir seu uso massivo e imediato a muito baixo custo (difusão e compartilhamento da informação geográfica).

Tem-se falado bastante sobre a questão da rejeição aos métodos quantitativos e às Tecnologias da Informação Geográfica, entre os geógrafos que seguem o paradigma humanista; isto ocorre, desafortunadamente, com bastante frequência, incluindo, às vezes, os métodos cartográficos. Um dos primeiros enfrentamentos nesse sentido o iniciou Stan Openshaw, que manifestou que os SIG tinham reabilitado os mais tradicionais métodos de trabalho dos geógrafos, como a "simples e desprezível técnica de sobrepor um mapa sobre outro" (Openshaw, 1991).

É evidente que a questão foi até extremos inconcebíveis, e afetou também (e principalmente) o ambiente universitário onde se ensina Geografia. Porém, ultimamente, é possível observar certa aproximação que podemos apresentar citando ao Prof. Horacio Capel, que, com muito acerto, aponta: 


\begin{abstract}
"No que se refere aos Sistemas de Informação Geográfica, sou da opinião de que seu ensino deve-se incorporar definitivamente aos estudos de Geografia. Também é de lamentar que a difusão da chamada geografia "humanista" e pós-moderna haja se unido a uma irreflexiva rejeição aos métodos quantitativos, que tão úteis, e inclusive indispensáveis, são em nossa ciência" (Capel, 2003).
\end{abstract}

\title{
Relação dos SIG com a Cartografia: A modelagem cartográfica.
}

Os mapas são, antes de tudo, abstrações da realidade, pois o mundo real é demasiado complexo para ser representado em sua totalidade; portanto, se faz necessário simplificá-lo, utilizando um modelo confiável que permita ganhar, em clareza e conhecimento, sobre o que existe e se manifesta no espaço geográfico. Os mapas se caracterizam como modelos complexos da realidade territorial, a partir das sete propriedades gerais enunciadas por Salitchev (1979): Abstração; Seletividade; Síntese; Dimensionalidade e Escala; Lei Matemática; Clareza; Semelhança Geométrica e Correspondência Geográfica.

É incontestável a intima relação existente entre os Sistemas de Informação Geográfica e a Cartografia. Porém, cabe apontar aqui que, em nossa opinião, o principal objetivo dos SIG é a execução da análise espacial, e consequentemente auxiliar no entendimento do espaço, na tomada de decisões e no planejamento territorial. É evidente, também, que os Sistemas de Informação Geográficos são utilizados do mesmo modo para a execução, ou visualização, de mapas e cartas, principalmente mapas temáticos, devido às conhecidas facilidades de manipulação gráfica e de grandes volumes de dados espaciais.

Tal e como afirmara Silvina Quintero (2006), a relação entre a Geografia e a Cartografia demanda repensar ambos os campos do conhecimento. Desta maneira, se para alguns enfoques disciplinares, em determinados contextos, os mapas perderam relevância na geração do conhecimento geográfico, não pode ser estendido para toda a disciplina, se observarmos a profunda transformação que vem acontecendo nas formas com que os geógrafos produzem e usam os mapas.

Na Geografia Humana, percebe-se um certo desinteresse pelos mapas, sugerindo que o trabalho com cartas e mapas deixou de ser um verdadeiro imperativo profissional para os geógrafos desde há varias décadas. Seguindo esta pauta, Ron Martin (2000) colocou no editorial da revista Transactions of the British Geographers, que apenas 50 das mais de 2.000 páginas de artigos recebidos nesse ano para publicação, incluíam mapas e admitiu que em várias áreas deste ramo da Geografia, as demandas profissionais implicam em mais habilidades literárias do que 
cartográficas. Em outras palavras, segundo o que diz Wheleer (apud Perkins, 2004: 381), alguns geógrafos tornaram-se "mapofóbicos".

Em nosso juízo, tais acontecimentos são lamentáveis, especialmente, porque no inicio da carreira de geografia, fomos instruídos de que a Cartografia era a linguagem natural de expressão gráfica do geógrafo. De fato, essa cisão tem sido objeto de nosso interesse desde quando publicamos o trabalho "Nuevas tecnologías en la geografía contemporánea: consideraciones sobre un debate español" (Pérez Machado R. P., 2009) na revista Biblio 3W, de Barcelona. No entanto, esse panorama começa a mudar e já aparecem, aqui e ali, no ambiente acadêmico, manifestações de interesse pela cartografia automatizada, os SIG, as Tecnologias da Informação, o geoprocessamento e, notadamente, pelo uso da cartografia interativa na internet, por parte geógrafos totalmente dedicados e envolvidos no Paradigma Humanista.

Simples reduções da realidade em escala, como por exemplo, as fotografias aéreas, são chamadas de modelos icônicos (Hagget, 1972). Porém, os mapas ainda podem ser vistos como modelos analógicos, onde as feições do mundo real são representadas por uma linguagem simbólica do tipo gráfica, onde os símbolos referem-se a porções abstratas de territórios, que podem aludir a partes da realidade. Os mapas podem gerar também o ponto de contato de uma abordagem quantitativa, na qual passam a ser um instrumento analítico, ajudando o pesquisador a ver o mundo real sob uma nova luz. Nesse aspecto, os mapas constituem modelos simbólicos, onde os fenômenos do mundo real são representados por expressões matemáticas abstratas (Hagget, ibidem)., Na medida em que vamos do mundo real, no sentido do modelo icônico, passando pelo analógico, até chegar ao modelo simbólico, existe um aumento do grau de abstração desses modelos, e no sentido oposto, aumenta o realismo.

Esta última abordagem mostra uma evolução da visão tradicional da Cartografia, quando o mapa deixa de ser simplesmente um veículo de informação visual, para também ser um instrumento de complexas análises de relacionamentos espaciais (Berry, 1993). Nesse sentido, o mapa digital trouxe uma revolução em termos da manipulação quantitativa dos dados cartográficos, possibilitando a aplicação de inúmeras técnicas matemáticas e estatísticas. Este contexto possibilitou o surgimento de uma verdadeira álgebra espacial, associada a uma modelagem cartográfica.

Segundo Tomlin (1990), a modelagem cartográfica envolve mapas e modelos, ou seja, modelos expressos através de mapas. Partindo desta visão, um modelo cartográfico pode ser simplificado a uma coleção de mapas, ou camadas de mapas pertencentes a uma área comum e operações entre 
seus elementos, o que os versados em Geoprocessamento denominam de "map overlay". Este modelo de camadas, capas ou layers (também denominados coverages, ou planos de informação) pode ser concebido como um conjunto de matrizes ou imagens flutuantes e ajustadas a um registro comum - na representação matricial ou raster -, onde cada camada de informação representa uma variável espacial, descrevendo um aspecto da realidade (Burrough, 1986 e Berry, 1993).

Dentro deste escopo, Tomlin (1990) traz uma visão formal sobre a linguagem de álgebra de mapas em sua descrição da modelagem cartográfica. Segundo este autor, as convenções fundamentais de uma modelagem cartográfica não se restringem a um SIG particular, no tocante à especificação de hardware e software. Ao contrário, por serem generalizadas, elas se relacionam a muitos sistemas possíveis no sentido que estabelecem a maneira em que os dados são processados e no modo em que o mencionado processamento é controlado. De fato, Tomlin desenvolveu uma linguagem computacional de alto nível para representar uma sequência de processamento utilizada em uma modelagem cartográfica. Segundo o autor, esta linguagem é composta de operadores e funções espaciais, que se classificam em quatro tipos: local, focal, incremental, e zonal. Cada grupo dessas funções é também combinado com determinados tipos de operadores matemáticos, estatísticos e lógicos. Uma função local calcula um novo valor para uma localização de uma camada em função do valor originalmente associado àquela localização na mesma camada, ou em camadas diferentes, assim elas se subdividem em funções locais de valor singular, ou como no último caso, de múltiplos valores. Os operadores utilizados são lógicos e matemáticos, incluindo, principalmente aqueles da álgebra booleana.

Em certo sentido, a modelagem cartográfica é similar às primitivas técnicas de mapeamento por sobreposição, envolvendo transparências em uma mesa de luz para o estudo do relacionamento entre múltiplos fatores espaciais. Esta técnica foi tradição da arquitetura de paisagem, popularizada pelo trabalho de lan McHarg (1969), e amplamente utilizada por gerações de geógrafos, antes do advento e popularização dos SIG e os sistemas de cartografia automatizada. Por outro lado, sua capacidade computacional, no caso de se utilizarem as técnicas de overlay (sobreposição) num ambiente digital, permite técnicas avançadas de análise espacial, como caracterização de uma vizinhança cartográfica e medidas de distância e conectividade, que estão mais relacionadas ao desenvolvimento recente do processamento de imagens e às funções e operações gráficas no ambiente vetorial. 
É importante mencionar que, embora exista uma tendência a reconhecer a modelagem cartográfica como um processo que ocorre exclusivamente no mundo raster ou matricial, ela também pode ser concebida no mundo vetorial, e, com efeito, existem vários SIG comerciais que operam segundo essa lógica. Acontece que, nos primórdios da difusão dos SIG os produtos que operavam seguindo o modelo de dados gráficos raster eram mais populares, mais simples, e especificamente a álgebra de mapas criada por Tomlin e utilizada por Marble, Calkings e outros notáveis pioneiros dessas tecnologias, era mais fácil de explicar e assimilar.

Por outra parte, Berliant (1987) enunciou a existência de dois paradigmas na Cartografia Geral que, para ele, são antagônicos e com eles, estabeleceu a ênfase em cada elaboração e aplicação: o paradigma cognoscitivo e o comunicativo. Em sentido geral, os mapas podem ser utilizados como material demonstrativo e de consulta ou, num contexto de maior relevância, como importantes geradores de novos conhecimentos e informações. Os mapas são considerados modelos de imagem simbólica que representam, de forma sintética, os espaços geográficos. Assim permitem definir os distintos elementos, estruturas, relações e funções dos fenômenos (sejam estes naturais ou artificiais) e derivar um conhecimento sintético (cognição). Mas também, podem e devem servir como difusores do conhecimento geográfico, ou seja, como um canal de comunicação que busca a transmissão de informação geográfica mediante a utilização de sistemas de representações visuais. Esta tendência está estreitamente relacionada com a semiologia cartográfica e a procura de modelos efetivos de comunicação gráfica. No momento de realizar qualquer mapa, estas duas posturas deveriam ser consideradas de forma integrada, garantindo, desta maneira, a máxima qualidade nos mapas elaborados. Em outras palavras, um mapa será eficaz na medida em que consiga, ao mesmo tempo, ser comunicativo e informativo; transmitindo, de forma clara e direta, conhecimentos e informações de forma sintetizada.

Pelo exposto, pode-se adotar, contemporaneamente, como conceito de modelagem cartográfica, a caracterização complexa de processos e fenômenos territoriais, criando e analisando mapas temáticos de inventários/diagnósticos, analíticos ou sintéticos, utilizando os métodos de representação cartográfica, os elementos dos mapas, assim como suas exigências dentro dos paradigmas atuais da cartografia (Candeau Dufat \& Pérez Machado, 2009). 


\section{A Geografia Humana.}

O crescente interesse pela espacialidade e o território dentro das ciências sociais iniciou um movimento destas disciplinas no sentido geográfico. Talvez o discurso sociológico mais conhecido a respeito seja o de Anthony Giddens (1995), que "redescobre" o espaço a partir dos trabalhos do geógrafo sueco Torstem Hagerstrand. Também, no contexto anglo-saxão, o discurso geográfico mais difundido sobre essa recuperação do espaço na teoria social no mundo, seja a o do geógrafo americano, de origem polonesa, Edward Soja (1990). Na França existem os trabalhos de Henry Lefebvre (2000), e no Brasil, brilha o notável geógrafo Milton Santos (2002), que dedicou grande parte de sua vida acadêmica a pensar e definir o espaço, em todas suas magnitudes.

Uma das maiores virtudes deste redescobrimento mútuo é que serviu para dar à Geografia, e aos geógrafos, sua legitimidade na Teoria Social. Esta foi uma boa entrada para que a Geografia se aproxime e dialogue mais intensamente com outros cientistas sociais, que também tratam a espacialidade.

Ao mesmo tempo em que nas outras ciências sociais ocorre esta espacialização, a Geografia vem experimentando um movimento inverso no sentido das disciplinas sociais. Tão relevante tem sido esta conjuntura atual da Geografia, que foi realizado no México o colóquio internacional "Los giros de la geografía humana", organizado pela Universidad Autónoma Metropolitana, Unidad Iztapalapa, entre 26 e 28 de novembro de 2008.

Ambos os movimentos resultam do reconhecimento da complexidade do mundo atual e da necessidade das aproximações interdisciplinares para a construção de novos corpos teóricos como vemos em Jacques Lévy, (1999), Neil Smith (2002), Nigel Thrift (1996), Mike Crang e Nigel Thrift (2000) e Milton Santos (2000).

Esta Geografia Humana utiliza um alto grau de empirismo com a correspondente perda de realismo no que diz respeito ao espaço euclidiano da Geografia Quantitativa. Em outras palavras, o que se estuda é difícil de ser posicionado em termos de coordenadas precisas - muito menos ajustado a uma escala e/ou projeção cartográfica - isto implica numa ruptura com as formas tradicionais de pensar o espaço geográfico, colocando em conflito a função epistemológica que até agora haviam cumprido os mapas na análise espacial tradicional, e, muito notadamente, naquela própria da cartografia digital computadorizada. Porém, em nossa opinião, isto não constitui um aspecto negativo, pelo contrário, tornou-se um tema central que tende a enriquecer as novas formas de pensar em Geografia. 
O espaço, desde esta perspectiva, se pensa em termos de ações, relações, processos, opiniões, participações, redes sociais, classes, grupos, interesses de vários tipos e organizações com várias estruturas que, não necessariamente, se delimitam, ou organizam, de maneira explícita sobre a superfície terrestre. Como já foi mencionada anteriormente, para Quintero (2006) esta é a razão pela qual os geógrafos humanos, principalmente do mundo anglo-saxão, tenham iniciado uma desvinculação com o uso dos mapas, chegando até sugerir que o trabalho com mapas não seria mais um imperativo dos afazeres geográficos.

Seguindo estes princípios, aparecem novos campos emergentes para a Geografia Humana, quais sejam: o desenvolvimento local, o estudo da mundialização, o estudo dos hábitos de consumo; a geografia dos gêneros, da vida cotidiana, da linguagem, da literatura, da religião, violência urbana e outros, assim como a recente abertura da disciplina para o que se conhece como as metodologias qualitativas. Também este movimento implicou na incorporação do deconstrucionismo para revisar o amplo papel dos geógrafos, com o poder de gerar uma forte autocrítica ao que o conhecimento geográfico-cartográfico estabelecido deformou durante muito tempo (Hiernaux \& Lindon, 2006).

Nesta abordagem se investiga como são estabelecidos os laços que unem os seres humanos com o meio geográfico, surgindo assim a denominada "topofilia" (Tuan, 1974). Suas análises se centram nos aspectos triviais da percepção, nas estruturas e respostas psicológicas comuns, no etnocentrismo e nas preferências individuais, nas posturas fenomenológicas e nas respostas diferenciadas através de valoração.

Para a Geografia do Meio Ambiente o enfoque antes exposto é essencial, pois coadjuva à aplicação das soluções propostas, e possibilita conhecer o nível de entendimento e autoreconhecimento que têm os atores locais que geram a degradação ambiental e a aceitação de sua corresponsabilidade para construir uma vontade coletiva de solução. Assim, se podem organizar campanhas efetivas de sensibilização e educação ambiental e avaliar a disponibilidade de programar medidas de melhoramento e atenuação dos impactos ambientais ajustadas às características de cada grupo social no território.

Casella (2007) afirma que existem vários níveis de consciência ambiental na população, que vão desde os que não conhecem, reconhecem, nem dão importância a este problema, os que vão ponderando sobre o crescimento econômico e a localização de infra-estruturas, estimulando variantes de mobilidade e de organização político-administrativa ou propostas de desenvolvimento urbano, sem levar em conta os impactos e as consequências gerados; até 
aquelas pessoas que perceberam os numerosos problemas ambientais das últimas décadas, além daqueles que devem ser enfrentados na escala local, regional, nacional e mundial. São conscientes de ter adentrado em uma crise ambiental global, estabelecendo a necessidade de nexo comum com fatores de essência produtiva, social, práticas de consumo sustentável e, em geral, do modo como a humanidade se relaciona com a natureza.

A determinação deste nível de consciência ambiental induz e possibilita a organização de campanhas adequadas para que os processos de produção internalizem os custos ambientais, também para que se realizem as mudanças de estilo de vida, de ética, de leis, de modelos produtivos e de técnicas, entre outras. A consignação desta consciência ambiental poderia apontar para o surgimento da Geografia do Meio Ambiente como uma disciplina emergente totalmente holística, que não só contempla a problemática ambiental, desde um ponto de vista técnico na caracterização espacial das relações sociedade-natureza, mas também desde a base teórica do uso das tecnologias. Isto estaria influenciado, sobretudo, pela aplicação das Tecnologias de Informação Geográfica em seu sentido mais amplo, na espacialidade geográfica e também considerado como um problema organizativo, ético, político e social.

\section{A Geografia Humana, a Cartografia e sua percepção.}

O impacto das Tecnologias de Informação Geográfica na nova Cartografia, como uma disciplina independente, com bagagens conceituais, instituições, procedimentos e incumbências profissionais específicas e próprias, levou ao surgimento de novos paradigmas em seu interior, relacionados com a construção e uso dos mapas (Quintero, 2006).

A segunda metade do século XX foi cenário de uma profunda transformação conceitual, institucional e tecnológica nas formas de conceber a cartografia; assim, as relações dos geógrafos com os mapas não poderiam ser analisadas independentes desses processos. Por outro lado, a vinculação da geografia profissional com o desenvolvimento da cartografia foi muito heterogênea, em distintos contextos. Segundo o expressado por Quintero (2006, pág. 528), em alguns países germanófonos e da Europa Central, assim como na Rússia e na América do Norte, abriram-se linhas de investigação teórica e empírica que converteram a Ccartografia em uma especialidade dentro da Geografia acadêmica e profissional (McMaster e McMaster. 2002; Fabrikant, 2001). Em outros meios, a concepção da Cartografia ficou ancorada nas visões mais tradicionais sobre os mapas, permanecendo o arcaico conceito que associa a Cartografia apenas com a representação 
correta da Terra (topografia) e a ideia de que se trata de uma técnica auxiliar da disciplina geográfica. Ainda assim, os diagnósticos coincidem no argumento de que "a Cartografia é um campo do qual (os geógrafos) temos desertado majoritariamente" (Quirós. 2001: pág. 31, apud Quintero, ibidem).

É muito provável que a centralidade, (e também a marginalidade), do "fazer mapas" na geografia contemporânea não dependa tanto do acesso atual à tecnologia como das tradições disciplinares que nutrem os enfoques predominantes em cada contexto; deste ponto deriva o papel da observação e da imagem na produção do conhecimento geográfico.

É sabido que o interesse pela quantificação nas ciências sociais, em geral, e na geografia em particular, acentuou-se a partir do início da década de 1950. O abismo entre os métodos quantitativos e qualitativos se manifestou em nossa disciplina através de uma série de dualismos irreconciliáveis, que só fomentou fronteiras rígidas e levaram alguns geógrafos ao estabelecimento da opção quantitativa por cima da qualitativa. A análise aqui proposta parte de considerar as profundas reformulações que se operaram a partir desse momento nos campos da Geografia e da Cartografia, e também nos conceitos de mapa e espaço. Assim concebidas, essas mutações podem se ordenar em quatro grandes processos.

O primeiro deles consiste na consolidação da Cartografia como disciplina acadêmica e profissional e independente no sistema científico internacional. Isto decantou a diferenciação dos saberes cartográficos e geográficos, iniciado em finais do século XVII em adiante.

O segundo processo remete às renovações conceituais dos anos sessenta e setenta do século XX, que transformaram a Geografia em uma disciplina teoricamente sofisticada e definitivamente posicionada no campo das ciências sociais. Isto provocou efeitos notáveis sobre sua relação com os mapas e a Cartografia.

Como derivação dos dois anteriores, o terceiro processo reside na profunda reelaboração da idéia do mapa, entre as décadas de 1970 e 1980, e que tem lugar tanto na área da Geografia Humana como no campo da Cartografia como disciplina.

Por último, o quarto processo consiste na emergência e massificação dos sistemas automatizados de informação e visualização geográfica. Há especialistas que coincidem em assinalar que os SIG alteraram o processo de consolidação como disciplina que a Cartografia vinha registrando até os anos oitenta do passado século. Desde outro ponto de vista, na Geografia Humana, a manifestação dos SIG, e outras tecnologias da informação geográfica, promoveram debates e 
provocaram perguntas, em terrenos muitas vezes evitados pela reflexão no âmago da disciplina, como os da ética profissional e a responsabilidade social no uso das tecnologias.

Percebe-se a presença ativa do chamado Paradigma Humanista, mediante o qual se tem construído uma visão espacial alternativa e independente, seguindo certos fundamentos iniciais dos estudos culturais de vertentes geográfico-antropológicas (Sauer, 1925, 1927, e 1963) e de outros relacionados com mapas mentais urbanos (Strauss, 1987); (Lynch, 1960). Vale dizer que não se deve considerar apenas como uma valoração paradigmática proveniente do desenvolvimento histórico disciplinar, nem de nenhuma corrente prévia específica, mas sim como uma nova forma independente, seguindo certos fundamentos iniciais.

Neste caso, a Geografia Humana centra sua atenção na relação do mundo interior com o mundo exterior ao ser humano, tais como a percepção, as atitudes e a valoração do meio geográfico. Consiste na interpretação dos mundos individuais dos habitantes de um território com o objetivo de ser considerada nas propostas e ações de atuação que se propõem nesse entorno espacial, centrando as analises nos aspectos comuns da percepção, as estruturas e respostas psicológicas massivas, o etnocentrismo e as preferências individuais, as posturas fenomenológicas e as respostas diferenciadas através da valoração. Tudo isto nos leva a debater o seguinte tópico.

\section{$O$ enfoque qualitativo}

Existem muitos caminhos que conduzem ao terreno da investigação qualitativa, e; à maneira de como se aplicam e se põem em prática estas opções científicas, dependendo do campo de onde provenha o pesquisador.

Para Denzin e Lincoln (1994) a investigação qualitativa é um campo muito amplo que atravessa disciplinas, problemas de investigação, métodos e perspectivas epistemológicas. Também constitui um conjunto de práticas interpretativas, as quais não se encontram ligadas a uma determinada teoria, ou paradigma em particular; não sendo privativos de uma ou outra área do conhecimento, sem seus próprios métodos, mas que se valem das aproximações, dos métodos e das técnicas de diversas disciplinas e perspectivas teóricas, como a etnometodologia, a fenomenologia, o feminismo, a psicanálise, os estúdios culturais, a teoria crítica, o positivismo e o pós-positivismo, entre outros. Esta pluralidade de enfoques certamente impede oferecer uma definição essencial. De fato, segundo esses autores, qualquer intento de produzir tal definição requereria uma análise qualitativa das circunstâncias nas quais a própria definição se produzira. 
Taylor e Bogdan (1984) fazem notar que embora este tipo de estudo aconteça desde o inicio das ciências sociais, poucos foram os investigadores dedicados a ele; grifando ainda que a época atual é um momento notável por causa do crescente interesse que se começa a observar por esta forma de aproximação. Para eles, o método qualitativo de investigação surgido ao longo do século XX se encontra vigente no novo milênio, pois representa uma grande oportunidade para gerar conhecimentos mais profundos sobre nossa situação no mundo.

Concordando com o dito antes, Baldus (1990), afirma que nos últimos anos do século XX se ressurgem os métodos qualitativos, essencialmente como uma reação diante das limitações do método positivista aplicado aos estudos sociais. Os métodos qualitativos enfatizam o estudo dos processos sociais. O pressuposto ontológico fundamental consiste em que a realidade se constrói socialmente e que, portanto, não é independente dos indivíduos.

Patton (1990) estabelece contrastes entre os elementos do que denomina método quantitativoexperimental e qualitativo-naturalista. À diferença do que se propaga na investigação quantitativa, o desenho da pesquisa qualitativa não se especifica por inteiro desde o começo, senão que vai evoluindo conforme transcorre o trabalho de campo. Parte-se de um foco de interesse, de certos planos para observar e entrevistar, de temas por explorar, mas não de variáveis operacionais, nem hipóteses estáticas preconcebidas, que se devam comprovar. Isto demanda, entre outras coisas, certa tolerância à incerteza e à ambiguidade, que estarão presentes durante o trabalho.

Para os métodos quantitativos é fundamental a cuidadosa construção e aplicação do instrumento com o qual se recolheram os dados, que se deve administrar de uma forma estandardizada, de acordo com procedimentos prescritos, para assegurar que meça o que se supõe que mede. Enfim, a validade do estudo encontra-se ancorada no instrumento.

Os métodos quantitativos concentram-se no estudo "objetivo" de fenômenos externos aos indivíduos; os métodos qualitativos privilegiam o estudo "interpretativo" da subjetividade dos indivíduos e dos produtos que resultam de sua interação. O aspecto central desta perspectiva refere-se ao significado que a realidade tem para os indivíduos e na maneira em que estes significados se vinculam à suas condutas. Essas diferenças são estudadas por Hammersley (1992), quem sintetiza em uma listagem as dicotomias gerais identificadas entre o método quantitativo e o qualitativo (ver Quadro 2).

O marco epistemológico das técnicas quantitativas se ampara no empirismo ou no positivismo lógico; enquanto as técnicas qualitativas se circunscrevem em perspectivas como a fenomenologia, a procura da compreensão ou da interação simbólica. O primeiro tipo de 
aproximação - a quantitativa - tende a estudar os eventos desde o exterior, a partir de um conjunto de interesses empíricos, que se impõem à realidade social com pouca, ou, às vezes, nenhuma referência ao significado que as observações têm para os sujeitos investigados. $\mathrm{O}$ segundo tipo - a qualitativa - interessa-se, fundamentalmente, com ponto de partida empírico, pela perspectiva dos atores, cuja experiência efetivamente vivida tratam de enfocar. Nos estudos quantitativos a amostragem estatística se utiliza para verificar teorias previamente existentes, enquanto que nos qualitativos a amostragem teórica fundamentada se leva a cabo com a finalidade de gerar teoria.

Quadro 2. Apresenta os dualismos identificados entre os métodos qualitativos e quantitativos, segundo Hammersley. Adaptado de Winchester, (1996, p. 19).

\begin{tabular}{|c|c|}
\hline Métodos Qualitativos & Métodos Quantitativos \\
\hline 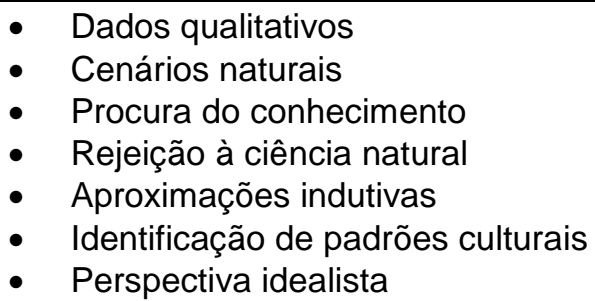 & $\begin{array}{l}\text { - } \quad \text { Dados quantitativos } \\
\text { - } \quad \text { Idenárifificação de comportamento } \\
\text { - } \\
\text { - Adoção da ciência natural } \\
\text { - } \quad \text { Conseximações dedutianas } \\
\text { - Perspectiva realista }\end{array}$ \\
\hline Entrevistas qualitativas & Medições quantitativas (questionários) \\
\hline $\begin{array}{l}\text { - } \quad \text { Pequenas amostras } \\
\text { - } \quad \text { Entrevistas extensas } \\
\text { - } \text { Amostragens não aleatórias }\end{array}$ & $\begin{array}{l}\text { - } \text { Grandes amostras } \\
\text { - } \text { Medições pequenas } \\
\text { - } \text { Amostragens aleatórias } \\
\end{array}$ \\
\hline
\end{tabular}

A oposição absoluta entre métodos quantitativos e qualitativos constitui-se em um falso dilema, já que a constatação e verificação para comprovar a validade dos trabalhos de pesquisa devem ser propostas pelos próprios pesquisadores, em cada caso especifico e, definitivamente, não cabe atribuição de regra, ou norma irrestrita, ao campo quantitativo, nem ao qualitativo. Em outras palavras, não há duvidas de que o método adequado para desenvolver uma investigação se elege racionalmente de acordo com as necessidades do problema a ser estudado.

Então, a investigação qualitativa em Geografia vem cobrir todo um espectro cientifico proveniente das ciências sociais. Este enfoque aporta ao conhecimento espacial desde a ótica dos atores sociais - o movimento inverso na geografia - e busca complementar o conhecimento geográfico que se realiza desde os enfoques quantitativos. Suas técnicas e métodos, respondem às perspectivas deslocadas das noções oferecidas pelas ciências "duras", 
atendendo à impossibilidade destas poderem aportar metodologias capazes de dar solução aos atuais problemas sociais e ambientais.

Os anos sessenta do século passado põem em discussão os temas vinculados aos caracteres estruturais da sociedade (a geografia radical). Logo, as leis e modelos estabelecidos não eram suficientes para compreender a importância da ação humana e seu comportamento espacial (em termos de percepção, imagens, etc.).

O centro da atenção nas pesquisas qualitativas em Geografia segue sendo a relação homemmeio, ou sociedade-natureza, mas, desta vez, enfatizando as condutas humanas que permitem compreender a forma em que se articula essa relação. Desta maneira surge a necessidade de recorrer a instrumentos e técnicas inovadoras que possibilitam concretizar investigações espaciais desde a perspectiva dos atores sociais. Assim, a pesquisa qualitativa trabalha com dados e informações provenientes das experiências subjetivas e busca questionar o que, desde a perspectiva quantitativa, seria inquestionável: busca compreender as visões existentes, desde a perspectiva destes atores, em relação às "realidades objetivas".

Partindo do marco epistemológico empírico hegemônico, os trabalhos baseados em métodos qualitativos, como por exemplo, as entrevistas, têm sido associadas a estudos de caso não generalizáveis, que não oferecem a explicação e apenas são reconhecidos como técnicas complementares de exploração e constatação. Vários autores coincidem em apontar que esta forma de procura permanente da complementaridade, em realidade subordina as técnicas quantitativas e, deste modo, se mantém e aceita o modelo hegemônico da ciência tradicional. Se bem é verdade que os geógrafos quantitativos têm exagerado nesta divisão, impondo a primazia de suas contribuições às de suas contrapartes qualitativas; não se pode negar que os geógrafos adeptos ao paradigma qualitativo também têm censurado a quantificação como insensível e não imaginativa. Desta maneira, em datas recentes, o surgimento de uma literatura que trata mais sistematicamente sobre os métodos qualitativos em Geografia Humana, evidencia ainda mais esta separação (García Ballesteros, 1998); (Pedone, 2000). Esta última autora assinala que, em numerosos estudos, a metodologia qualitativa cai em algumas das limitações observadas nos métodos quantitativos, ao supor a existência de uma única forma de abordar a realidade e propor, para todo tipo de investigação, um conjunto de procedimentos e passos pré-fixados, desta vez na prática qualitativa, para atingir seus objetivos. 


\section{Os mapas mentais}

O mapa mental tem-se definido ao mesmo tempo como conceito e como documento geográfico. Ele foi proposto por geógrafos anglo-saxões durante os anos 60, posteriormente encontrou uma ressonância relevante na década de 1970, ligado à "Geografia da Percepção", para ser, em seguida, menos frequente. Sua utilização volta a aparecer nos primeiros anos do século XXI, desta maneira completando, aparentemente, um dos ciclos paradigmáticos enunciados por Buzai (1999). Segundo Jean-François Stassak (apud Lévy e Lussault, 2003), o termo - mapa mental recobre três significados, que remetem a três diferentes "realidades":

$\checkmark$ Trata-se de um mapa, desenhado a mão livre e sem nenhuma ajuda exterior, ou seja, feito de memória, por alguém a quem se demanda que represente um espaço que ele conhece, mais ou menos. Este mapa é uma representação inexata do espaço de referência ${ }^{4}$. Alguns pesquisadores chegaram, aliás, até calcular a deformação e a distorção entre o espaço expresso num mapa mental e o espaço "objetivo", ou euclidiano. Um claro exemplo disto pode-se encontrar no trabalho de Collete Cauvin (2002). A pesquisadora trabalha com as posições relativas de pontos de referência obtidas nos mapas mentais (croquis) de diversos indivíduos entrevistados, comparando-as com suas posições homólogas no mundo real. Assim, utilizando regressões bidimensionais, foram construídas as figuras que mostram o espaço distorcido (anamorfose ${ }^{5}$ ), que representa a configuração cognitiva de cada sujeito estudado. A Figura 2 mostra três versões consecutivas realizadas pelo mesmo indivíduo: um ciclista em Strasburg. Os entrevistados identificaram locais precisos na cidade (pontos cognitivos), que foram comparados, estatisticamente, com sua localização real (pontos de referência).

Mesmo onde ele se verifica distorcido, esse é justamente o sentido da expressão mapa mental. Ele será a imagem exata, a transcrição da representação mental do espaço em questão, no entendimento da pessoa que realiza o exercício. O mapa mental será então uma estrutura cognitiva da percepção do espaço ${ }^{6}$. Sua existência suscita debates: uma coisa é ter na cabeça um mapa mental e ser capaz de cartografá-lo, como resposta a um pedido (mesmo mal executado), outra coisa é ter na cabeça um mapa mental, quer dizer,

\footnotetext{
${ }^{4}$ Grifo nosso.

5 Anamorfoses geográficas são representações de mapas baseados em alguma escala predefinida. Elas não apresentam apenas a escala cartográfica porque não são representações reais dos mapas levando em conta seu território e sim diversas outras variáveis como, por exemplo, a população de uma região, o tempo de viagem, o índice de natalidade e/ou mortalidade, entre outras.

${ }^{6}$ Grifos nossos.
} 
de dispor em sua memória, não somente imagens ou conhecimentos de um espaço, mas uma verdadeira representação cartográfica dele. Isso permite chegar a retificar, a naturalizar o mapa, a lhe conceber como uma verdadeira estrutura da percepção e da concepção do espaço (Figura 3).

O mapa desenhado não representa forçosamente uma boa imagem da estrutura cognitiva, mas pode, por exemplo, servir para medir uma atitude expressa no desenho e na cartografia, os geógrafos elaboraram mapas mentais que são representações básicas que sintetizam a relação com o espaço das pessoas pesquisadas ${ }^{7}$. Sobre um fundo de mapa clássico (euclidiano), diferentes figuras (isolinhas, símbolos, cores etc.) mostram como tal espaço, tal linha ou tal ponto são conhecidos, mencionados, apreciados, praticados (Figura 4).Os debates e as críticas produzidas pela utilização dos mapas mentais têm sofrido períodos de intensificação ao longo dos últimos anos do século $\mathrm{XX}$, adentrando ao século XXI. Os geógrafos mais radicais sugeriram que os mapas mentais deveriam, sobretudo, ser realizados pelos próprios geógrafos a fim de revelar os fundamentos implícitos de seus modelos cognitivos do espaço. O mapa mental poderia então possuir um papel na análise reflexiva das práticas científicas (Stassak apud Lévy e Lussault, 2003).

${ }^{7}$ Grifo nosso. 


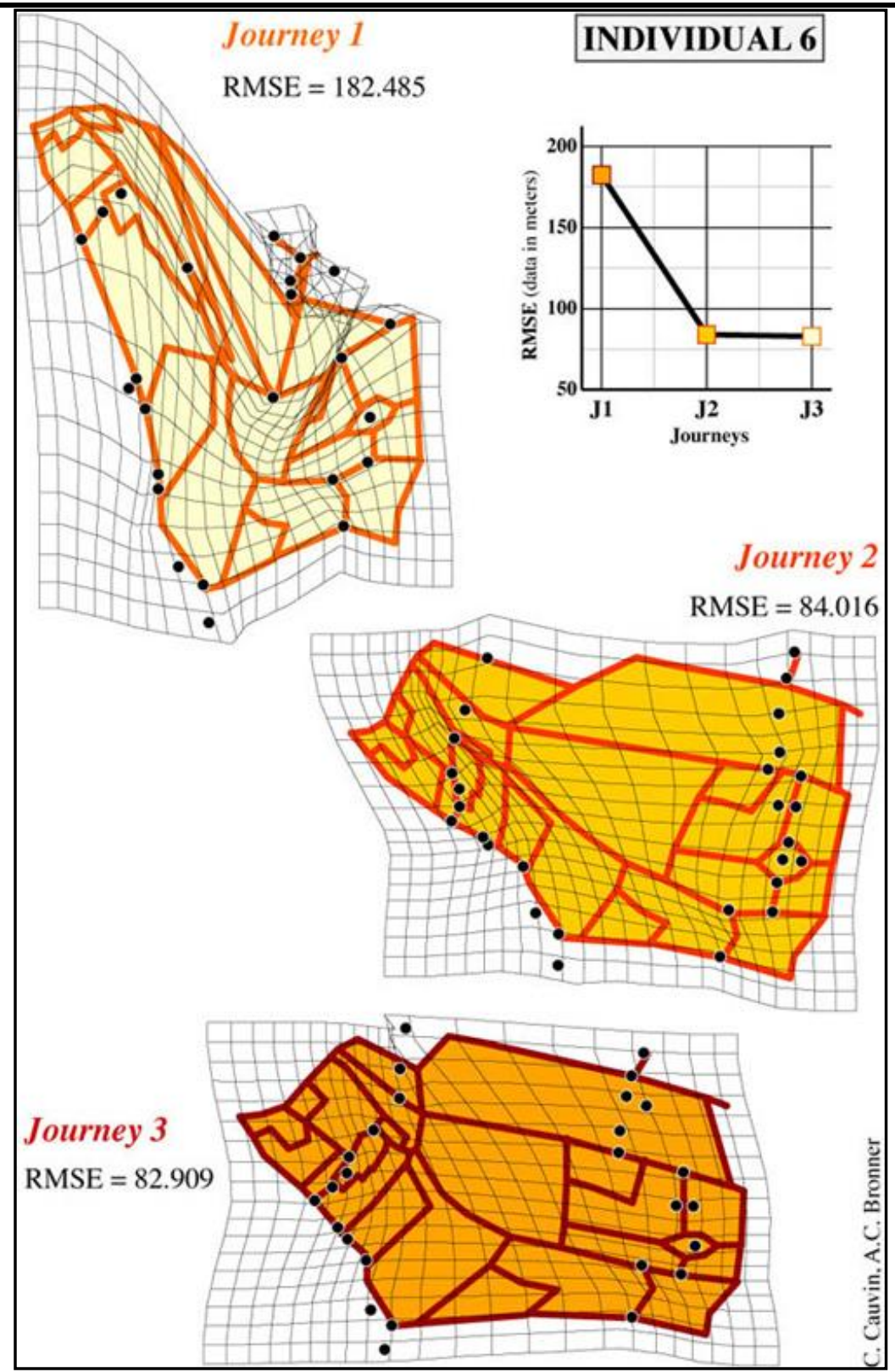

Figura 2. Exemplo da comparação de mapas mentais do individuo 6, com análise do erro da localização (distorção), expressa na anamorfose. Note-se que o Erro Médio (RMSE) diminui notavelmente do primeiro para o segundo percurso e depois estabiliza. Fonte: Collete Cauvin (Cognitive and cartographic representations : towards a comprehensive approach, 2002) 


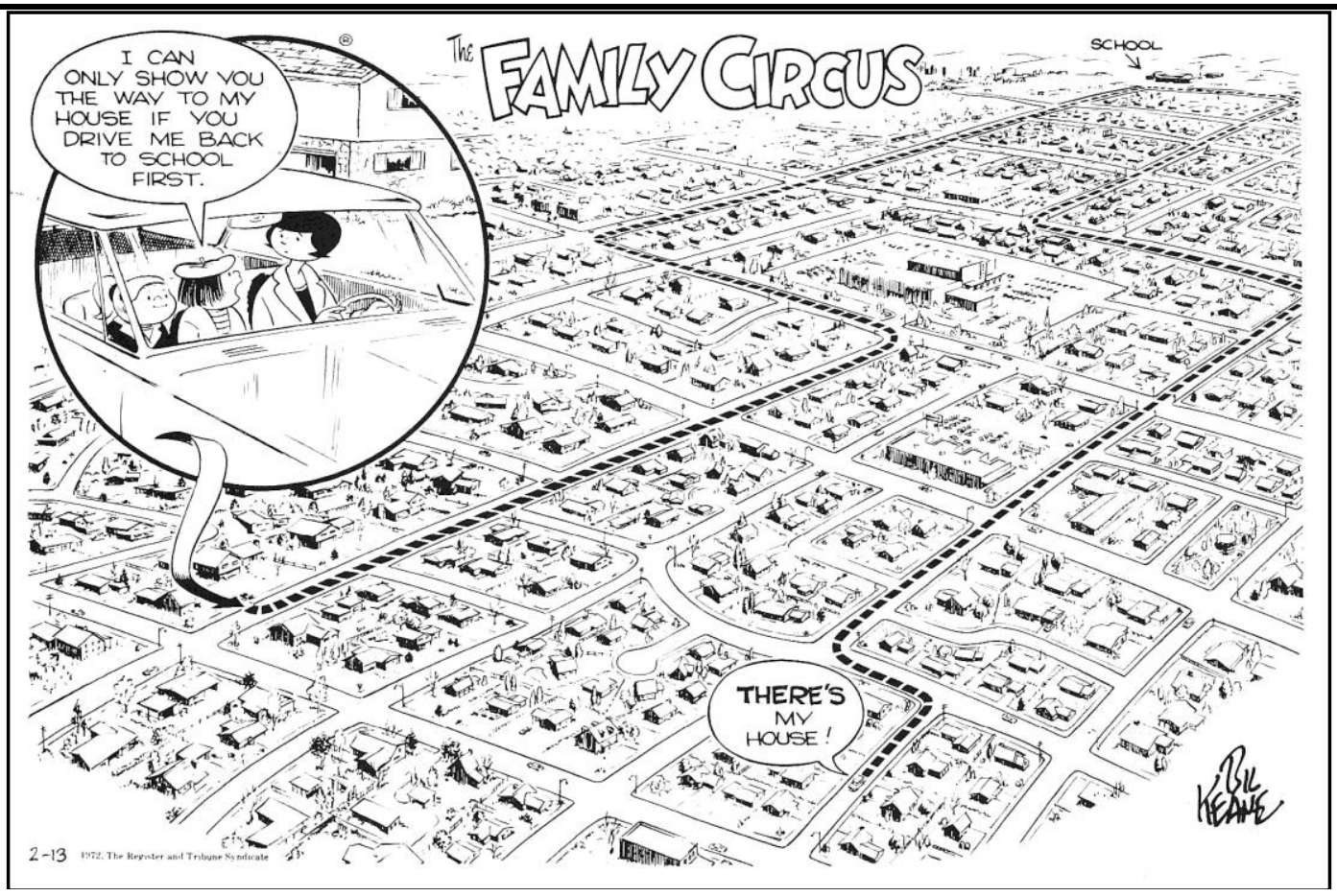

Figura 3. Charge mostrando estrutura cognitiva expressada pelo mapa mental de uma criança. No texto: "Eu só posso te mostrar o caminho até minha casa se você me levar primeiro até a escola". Fonte: Phillip C. Muehrcke (Map use:

Reading, Analysis, and Interpretation, 1986)

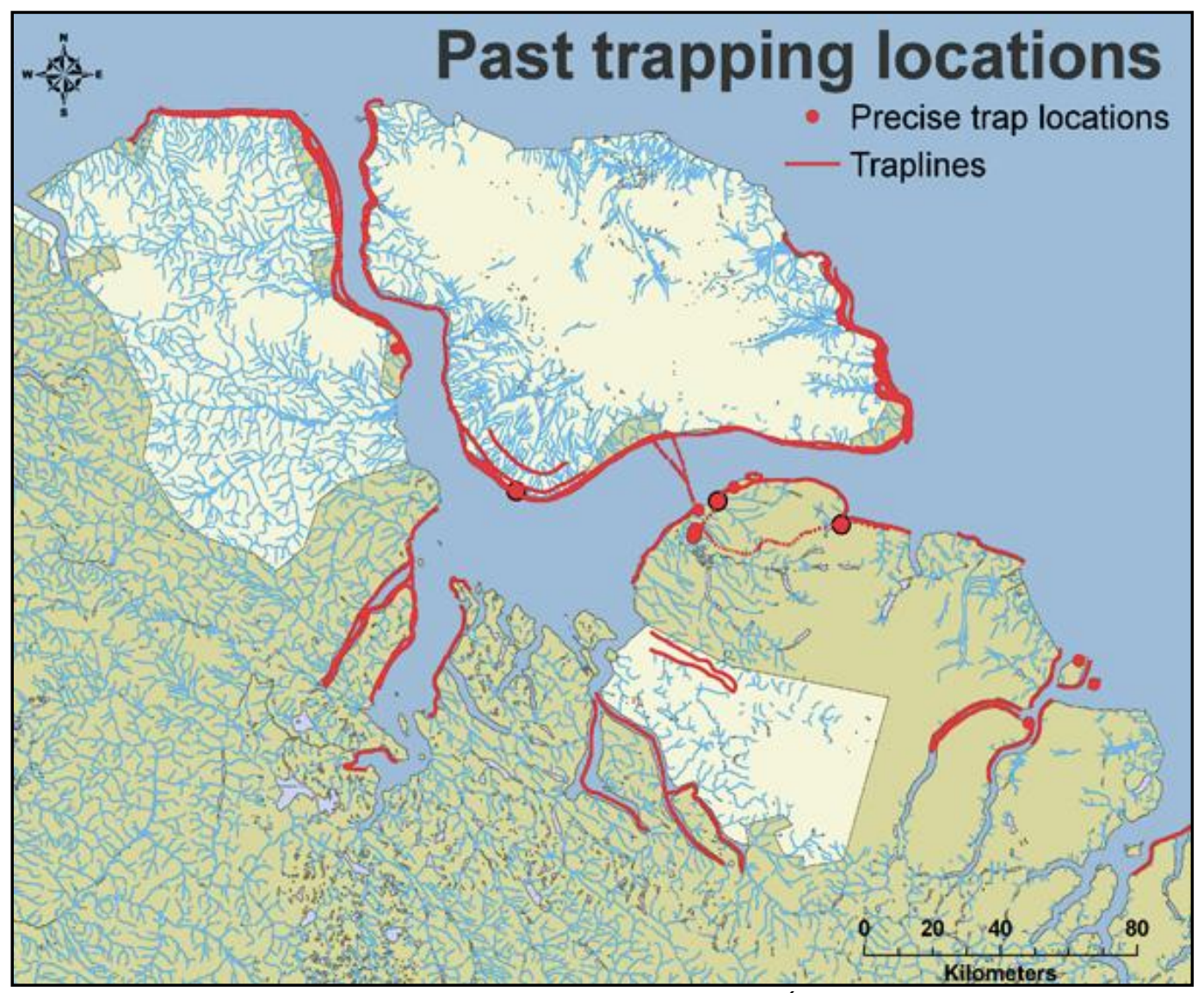

Figura 4. Antiga localização das armadilhas para capturar a Raposa do Ártico sobre um fundo de mapa clássico (euclidiano) Fonte: Ecological Studies and Environmental Monitoring at Bylot Island Sirmilik National Park (Gauthier, et al., 1988). 
Um estudo realizado ao longo de três anos no Estado de São Paulo sobre a cognição espacial dos macacos (Presotto, 2009) determinou que os macacos-prego (Cebus nigritus), além do mecanismo de orientação egocêntrico ${ }^{8}$, podem se utilizar de um sistema de orientação alocêntrico ${ }^{9}$ lembrando a capacidade cognitiva dos seres humanos - para a busca de alimentos na mata atlântica. O trabalho mostrou que os animais recordam a localização de objetivos espaciais como fontes de frutos e sítios de dormida, pois se deslocam mais rapidamente, e de forma mais linear, para esses locais do que quando estão forrageando por recursos dispersos. Além disso, memorizando esses locais, os animais podem revisitar as fontes utilizando atalhos e criando caminhos novos, fazendo uso de um sistema alocêntrico. Ou seja, a maior novidade do estudo é o fato de que os macacos podem atingir um mesmo local a partir de diferentes pontos, fazendo caminhos novos, da mesma forma que o fazem os humanos. Deduz-se que para conseguir isto na mente dos primatas existe, mesmo que de forma rudimentar, um mapa mental.

Os resultados da pesquisa, que foram utilizados na tese de doutorado da geógrafa Andréa Presotto (2009), são frutos da parceria entre as áreas da geografia e da psicologia experimental. A geografia levou sua contribuição à área de comportamento animal, com tecnologias de apoio e metodologias para o estudo da utilização do espaço (mediante a Cartografia e utilização de GPS e Sistemas de Informação Geográfica), enquanto a etologia cognitiva contribuiu com teorias e metodologias para o estudo do comportamento dos animais.

\section{A Neogeografia}

No ambiente não acadêmico da vida cotidiana dois acontecimentos têm gerado um notável interesse: a popularização das tecnologias de posicionamento global - Global Positioning Systems (ou GPS) - e a explosão do uso de imagens satelitais promovidas pelos sistemas de consulta e visualização Google Earth e Google Maps. Especialmente este último (mas também a junção de ambos) tem propiciado o surgimento da chamada Neogeografia.

O termo Neogeografia (nova geografia) descreve o fenômeno social em torno da massificação dos mapas virtuais, o acesso à anotação neles, e o barateamento dos dispositivos de posicionamento tais como o GPS. Assim, o vocábulo vem a definir aqueles instrumentos e técnicas geográficas utilizadas para realizar atividades pessoais, ou de um grupo de usuários, não especialistas na

\footnotetext{
${ }^{8}$ Quando a localização de um objeto está relacionada à posição do próprio indivíduo.

${ }^{9}$ Quando a localização de um objeto está relacionada à localização de outros objetos, ou seja, a posições externas ao indivíduo.
} 
análise geográfica, já que seu objetivo primário é o uso informal e não o analítico. Ela é uma expressão, em seu mais recente sentido, que deriva do novo uso que se está dando à cartografia na Internet, por parte de usuários massivos. Esta nova geografia é o resultado da liberdade de acesso ao georeferenciamento de eventos ou lugares, à colocação de etiquetas em conteúdos geo-espaciais - geo-etiquetamento -, à fácil integração de recursos em ambiente web mediante o uso de APIs e à utilização, cada vez mais cotidiana, de GPS e de dispositivos de posicionamento integrados - telefones celulares, smart phones, PDAs e navegadores.

Embora este termo tenha sido empregado, anteriormente, na literatura cientifica, pelo filosofo Francês Francois Dagognet (1977) quem o utilizou no título de sua monografia "Une Epistémologie de l'espace concret: Néo-géographie", a palavra foi utilizada, pela primeira vez, em um contexto relacionado com a internet pelo Curador da Biblioteca da Cidade de San Francisco, Kenneth Dowling, em relação ao estudo das comunidades "on line" na década de 1990.

Antes de ser consagrado o vocábulo, no contexto atual, como "neogeografia", as palavras que imediatamente o precederam (em Inglês) foram: "the geospatial Web" (a rede geo-espacial); "the geoaware Web" (a rede geo-consciente); "Where 2.0" (onde? 2.0); "a dissident cartographic aesthetic" (uma estética cartográfica dissidente); e "mapping and counter mapping" (mapeamento e contra-mapeamento). Todas estas expressões levantaram o conceito, agora concentrado na Neogeografia, da Web 2.0, ao redor do intenso interesse público por mapas e imagens digitais, mapeamento e tecnologias geo-espaciais que ocorreram com o lançamento dos programas Google Maps, Google Earth, Street Maps e todos seus derivados e similares. Surgiu também, como uma evolução dentro da Neogeografia, o conceito "Notopia" - no+topia, não lugar - (Papadimitriou, 2010).

Como foi expresso acima, a Neogeografia está estreitamente enlaçada ao fenômeno da Web 2.0, tanto que as pessoas são as que publicam, sem que exista a possibilidade de censura, seus pontos de vista de maneira expressiva e criativa. Com a Neogeografia essa capacidade se amplia a uma consciência de lugar, e também à expressão livre e criativa dos lugares.

Rana e Joliveau (apud Goodchild 2009) assinalam que o passo de uma geografia acadêmica ou "paleogeografia" à nova geografia "neogeografia" se caracteriza por um "desdesenho" dos limites entre os papéis tradicionais de sujeitos produtores, comercializadores e consumidores de informação geográfica.

$\mathrm{Na}$ Neogeografia a liberdade criativa é o primeiro conceito a ser levado em conta, não obedecendo nenhum critério daqueles que hão definido, anteriormente, a ciência da geografia, da 
cartografia tradicional, nem do geoprocessamento. Por isso se fala da Neogeografia como fenômeno social e de uma nova relação com os espaços físicos. Ela cria territórios virtualmente, toda vez que os usuários, ou comunidades dadas, criam mapas, usando seus próprios critérios de espacialidade, temporalidade, sentido criativo, ânimo de ficção, compromissos com causas territoriais e, em geral, quaisquer iniciativas que envolvam as redes digitais e o espaço físico. 0 fato mais importante por trás deste conceito é que tais ações são executadas de moto próprio, voluntariamente. Por conta dessa forma de agir e pensar, o caminho lógico tem levado à elaboração de mapas coletivos, colaborativos, caracterizados, especificamente, como "open" (aberto), público e "free" (livre), usando os termos em inglês, referindo-se não apenas à liberdade antes mencionada, mas também à sua gratuidade, ao custo zero. Projetos globais colaborativos como o OpenStreetMap (The State of the Map ${ }^{10}$, 2013) e o aplicativo Waze para smart phones, são um claro exemplo deste argumento na aplicação da Neogeografia.

\section{A cartografia participativa e colaborativa.}

Entre os métodos qualitativos mais utilizados, atualmente, ressaltam-se as entrevistas em profundidade, os métodos fenomenológicos, etnográficos e, principalmente, a observação participativa e os grupos focais. Se há verificado uma junção interessante, e proveitosa, entre as tecnologias da informação geográfica e as metodologias de pesquisa colaborativa, produzindo instrumentos de simulação e elaboração multidisciplinar e participativa, conhecidos como jogos de papéis. Nestes se pressupõe a integração das várias representações e conhecimentos, o que garante sua legitimidade e a possibilidade de utilizá-los como plataforma de mediação na discussão dos conflitos socioambientais.

Como exemplo de aplicação prática desses jogos de papéis podem-se citar dois exemplos documentados em estudos sociais na Região Metropolitana de São Paulo, Ter'Águas e ÁguAloca (Ducrot, Camargo, \& Jacobi, 2004). Ambos os jogos, computadorizados, foram desenvolvidos com o software francês CORMAS (www.cormas.fr). O primeiro, Ter'Águas, foi programado para simular a negociação sobre planejamento do uso do solo em regiões periurbanas. O segundo, ÁguAloca, foi desenvolvido para abordar a questão da gestão da água, ou seja, a articulação entre

10 Conferência anual internacional do OpenStreetMap. A de 2013 aconteceu em Birmingham, Reino Unido, e a primeira reunião State of the Map, aconteceu em Manchester em 2007. 
alocação de água entre usuários múltiplos, a evolução da sua qualidade e as implicações para a agricultura.

Como situação antecedente à concepção de produtos de simulação computadorizada mais sofisticados, como os supracitados, deve-se mencionar que, desde os anos 1990, disseminaram-se mundialmente diversas iniciativas de mapeamento com a proposta de incluir as populações locais nos processos de produção de mapas para a tomada de decisões comunitárias.

Estas práticas têm envolvido diversas instituições tais como agências governamentais, ONGs, organizações indígenas, organismos multilaterais e de cooperação internacional, fundações privadas, e universidades, entre outras. Utilizando-se de diversas terminologias, tais atividades são reconhecidas, no debate internacional, como iniciativas de "mapeamento participativo". Para Herlihy e Knapp (2003), o mapeamento participativo é aquele que reconhece o conhecimento espacial e ambiental de populações locais e os insere em modelos mais convencionais de conhecimento. Suas raízes metodológicas estariam ligadas ao que se tem chamado de "observação participativa" e "metodologias de pesquisa colaborativa". Assim é que métodos de pesquisa participativa combinados com as Tecnologias da Informação Geográfica, como os SIG, o sensoriamento remoto e o uso de dispositivos GPS, foram adotados para a elaboração dos mapas, gerando um novo horizonte de produção e uso de tais instrumentos de representação espacial, assim como também um novo espaço de intervenção para as referidas instituições.

Tais projetos de mapeamento comunitário envolvem diretamente os membros da comunidade no levantamento do uso da terra e das fronteiras de seus domínios. As tecnologias empregadas variam muito. Em sua versão mais simples, os mapas podem ser feitos à mão, tendo por base os contornos de mapas oficiais ampliados. Nesses modelos os membros das comunidades locais podem pintar áreas com vegetação, estradas, dados sobre uso da terra, lugares povoados e as fronteiras das terras reivindicadas.

Outros exercícios de mapeamento utilizam recursos e técnicas de geoprocessamento principalmente GPS e imageamento por satélites - ou tradicionais de levantamentos aerofotogramétricos - para registrar dados nos mapas. Embora essas técnicas permitam aos membros das comunidades decidirem o que vai ser colocado nos mapas, elas dependem, em certa medida, de que pessoal treinado externo, em geral vinculado a ONGs, prepare os mapas básicos, registre os dados de campo diretamente nos mapas, ou no computador, e imprima os mapas finais. 
Segundo alguns autores (Chandler, Olson, Deroy, \& Brodeick, 2006), as experiências pioneiras de mapeamento participativo e uso de um Sistema Participativo de Informações Geográficas (SPIG) remontam ao Canadá de três décadas atrás. O primeiro estudo sistemático reconhecido referia-se a um projeto de Uso e Ocupação de Terras pelos Esquimós. Nesse projeto, centenas de Inuits esquimós - foram entrevistados no início dos anos 1970, o que resultou em mais de duzentos mapas de atividades sazonais de subsistência. (Chandler, et. al., ibidem).

No entendimento de Chapin et al (2005), que acompanham as experiências especificamente associadas a povos indígenas, outras regiões foram objeto de um menor número de estudos na época, como as áreas tropicais da América Latina, África e Ásia, mas também os Estados Unidos. Chapin et al (ibidem) acreditam que os atores envolvidos nestes mapeamentos não encontraram incentivo ou tempo para escrever sobre suas experiências, ou então ficaram relutantes em tornálas públicas.

Como exemplo seria possível mencionar o episódio ocorrido no início da década de 1980, em ocasião das reuniões para iniciar o planejamento de ocupação de uma empresa agropecuária na estrada Manaus - Caracaraí (BR174) na Amazônia. Na época, muitos dos habitantes locais, garimpeiros e, especialmente, os membros da tribo Atroaris acharam que a vegetação estava representada de forma absurdamente equivocada, ao observar a impressão das imagens de satélite em falsa cor, onde a floresta deles aparecia pintada em diferentes tonalidades de vermelho, (Mário De Biasi comunicação pessoal).

Existem documentadas no Brasil numerosas experiências ditas de "mapeamento participativo" que foram promovidas por ONGs, entidades ambientalistas, entidades associativas de quilombolas, indígenas etc. Tanto é assim que em dezembro de 2008 celebrou-se, na Casa da Ciência, no Rio de Janeiro, o Seminário "Cartografias Sociais e Território", onde se discutiram importantes temas de interesse relacionados com o assunto, como:

$\checkmark$ Cartografia social e mapeamento participativo no Brasil.

$\checkmark$ Cartografias e tramas territoriais: contextos jurídico-político-fundiários e étnicos dos mapeamentos.

$\checkmark$ Financiamento, produção e controle da informação espacial - de quem é o mapa?

$\checkmark$ Técnicas de representação espacial e participação.

$\checkmark$ Mapeamento do território e organização da sociedade.

$\checkmark$ Planos diretores e mapeamentos participativos urbanos. 
Também se apresentaram os vídeos "Mapeamentos Participativos e Povos Indígenas: passo para autonomia ou sujeição à tecno-ecocracia?" e "Amazônia - uma nova cartografia - lauaretê."

Em diferentes lugares do mundo está ocorrendo essa retomada à cartografia e ao mapeamento colaborativo e/ou participativo. São notáveis os trabalhos produzidos por professores da Faculty of Geo-Information Science and Earth Observation - ITC of the University of Twente, na Holanda, que tem aplicado essas técnicas qualitativas não só nas salas de aula deste renomado instituto se não também em diversos países do mundo (McCall \& Minang, 2005).

$\mathrm{Na}$ Espanha, destaca-se atualmente a corrente da denominada Cartografia Cidadã, que tem sido definida como uma prática em permanente construção, auto-reflexiva, admitindo e favorecendo a multiplicidade de agentes cartógrafos, de métodos e meios cartográficos. A Cartografia Cidadã tem caráter político, pois a população humana não está apartada do território. Sua atividade não é neutra, já que seus praticantes estão, por definição, situados desde o inicio, se expressam e agem desde um lugar concreto e desde um concreto campo de forças.

A Cartografia Cidadã é transparente em todos seus aspectos, desde sua codificação e tecnologias empregadas, aos projetos em processo e seus resultados. Sua força reside no trabalho colaborativo da multiplicidade de integrantes no território. A aparição de tecnologias cibernéticas e telemáticas de uma grande potência permite obter, de forma mais fácil e econômica, desenvolvimentos inéditos da expressão textual discursiva e do que se pode denominar semiótica das imagens. Desta forma, são produzidas sínteses integradas, ao mesmo tempo em que se abrem possibilidades criativas importantes. (Hackitectura, 2009)

No México destaca-se o trabalho realizado no Instituto de Geografia da Universidad Nacional Autónoma de México - UNAM, onde, em 2006, organizaram-se as Oficinas de Participação Cidadã, nos Programas de Ordenamento Ecológico e Territorial. Sem dúvidas, este é um excelente exemplo de aplicação das técnicas quantitativas na Geografia do Meio Ambiente.

Ao comentar sobre os resultados obtidos, os pesquisadores desta instituição relataram que o desenvolvimento de entrevistas, relatos e outras técnicas de investigações qualitativas no desenvolvimento dos Programas de Ordenamento Ecológico e Territorial minimizaram os conflitos resultantes do aproveitamento e uso do território; buscando o consenso de projetos ou planos encaminhados à prevenção, compensação, mitigação ou reorientação de atividades produtivas e sócio-culturais, assim como incorporaram as instituições implicadas no seguimento destas propostas. Possivelmente ditos programas se constituam em mecanismos integradores para colaborar no desenvolvimento regional e atuar como um instrumento de planejamento. 


\section{À guisa de conclusão.}

Da mesma forma que o objeto e o método da Cartografia deveriam ser repensados em virtude das novas tendências da cartografia contemporânea, como a introdução da automação, o progresso das áreas temáticas e o sucesso do uso do mapa como recurso da pesquisa científica (Salitchev, 1979), a relação entre a Geografia e a Cartografia deve ser revista também (Quintero, 2006), bem como a possibilidade de combinar, de forma conciliada e não antagônica, os métodos qualitativos e quantitativos na Geografia Humana deve ser objeto de análise exaustiva e debate construtivo. Embora esta ideia não seja nova (Philip, 1998), dada a disputa em torno da possível combinação de ambas as aproximações, na investigação social e na reconsideração de incluir métodos de validação para outorgar rigor às pesquisas qualitativas (Baxter \& Eyles, 1887), em nossa opinião isto está começando a acontecer agora, no início do século XXI. Não apenas no contexto anglosaxão, senão também no mundo ibero-americano (García Ballesteros, 1998); (Hiernaux \& Lindon, 2006).

Embora para alguns enfoques disciplinares, em determinados contextos, os mapas não sejam predominantes na geração do conhecimento geográfico, isto não pode ser estendido à toda a disciplina, considerando a profunda transformação que se vem manifestando nas formas em que os geógrafos veêm, criam e usam os mapas. Especial importância deve-se conferir ao ressurgimento dos paradigmas qualitativos e quantitativos, à popularização do uso das tecnologias da informação geográfica e do sensoriamento remoto, à massificação do uso de dispositivos de posicionamento global e, principalmente, ao crescente acesso à internet e aos programas de visualização geográfica, através de dispositivos celulares móveis.

Os SIG desde o ponto de vista da Geografia não pode seguir sendo apenas um dos elementos integrantes das Tecnologias da Informação Geográfica; devem, sim, ser considerados como metodologias que propõem novas formas de se fazer Geografia ou ainda - e esse momento já se aproxima - como parte da Ciência da Informação Geográfica.

Para atingir esse objetivo, será necessário, em primeiro lugar, que se reforcem os fundamentos teóricos, conceituais e, inclusive, ontológicos mais profundos (Chuvieco, et al., 2005). Também, que os programas de cartografia automatizada que a integram sejam capazes de estabelecer as funções dos mapas dentro dos paradigmas atuais da Cartografia, onde se instauram como modelos complexos da realidade para facilitar o entendimento e a compreensão espaciais. Ainda, 
como meios de análise espacial e comunicação visual e não apenas como artefatos resultantes de processos matemáticos de projeção cartográfica e receptáculos de dimensões físicas.

Neste último contexto é que mencionamos aqui os mapas inexatos; essas novas formas de cartografar não irão oferecer a exatidão cartográfica, nem a acurácia ${ }^{11}$ que se espera nas cartas topográficas ou nas cadastrais urbanas. Porém, sim, terão toda a exatidão que for atribuída pela representação mental do espaço em questão e pelo arcabouço cognitivo da percepção conferida por seus criadores.

Fica claro que, por enquanto, as Tecnologias da Informação Geográfica, em geral, e os Sistemas de Informação Geográfica em particular, deverão incorporar a seu acervo de funções novas opções de análise qualitativas para atender aos requerimentos apresentados pelas necessidades das pesquisas, nas diferentes áreas da Geografia, seja esta Humana ou Física, o qual constitui, certamente, um novo desafio.

\section{BIBLIOGRAFIA}

Baldus, B. (1990). Positivism's Twilight. Canadian Journal of Sociology, 15, pp. 149-163.

Baxter, J., \& Eyles, J. (1887, Dec). Evaluating Qualitative Research in Social Geography: Establishing 'Rigour' in Interview Analysis. Transactions of the Institute of British Geographers, Volume 22 (Issue 4), pp. 505-525.

Berliant, A. (1987). Problemas actuales de la Cartografía y de la utilización de los mapas. La Habana: Facultad de Geografía, Universidad de La Habana.

Berry, J. K. (1993). Beyond Mapping: Concepts, Algorithms, and Issues in GIS. Wiley.

Burrough, P. A. (1986). Principles of Geographical Information Systems for Land Resources Assessment. Monographs on Soil and Resources Survey. Oxford: Oxford University Press.

Buzai, G. D. (1999). Geografía Global (Primera Edición ed.). Buenos Aires: Lugar Editorial.

Candeau Dufat, R. V. (2009). La Geografia Física frente a la Tecnologia de la Información Geográfica. En A. I. Geraiges de Lemos, \& E. Galvani, Geografia, tradições e perspectivas:

\footnotetext{
${ }^{11}$ Acurácia (anglicismo de accuracy) de uma estimativa é uma medida da correlação entre o valor estimado e os valores das fontes de informação, ou seja, mede o quanto a estimativa que obtivemos é relacionada com o "valor real" do parâmetro estudado. Ela nos informa o quanto o valor estimado é "bom", ou seja, quanto o valor estimado é "próximo" do valor real provendo a "confiabilidade" daquela estimativa ou valor. No contexto cartográfico do espaço euclidiano, é considerada como uma medida da exatidão.
} 
Interdisciplinariedade, meio ambiente e representações (Primeira Edição ed., págs. 245-264). São Paulo: Clacso / Editora Expressão Popular.

Candeau Dufat, R. V., \& Pérez Machado, R. P. (2009). Las respuestas de la Tecnología de Información Geográfica ante los nuevos enfoques y replanteamientos de la Geografía. Anales del 12 Encuentro de Geógrafos de América Latina - 12 EGAL. Montevideo: 12 EGAL.

Capel, H. (15 de Diciembre de 2005). Las TIG en los concursos de habilitación para profesores titulares de geografía humana. Una cuestión nada anecdótica. Biblio 3W, Revista Bibliográfica de Geografía y Ciencias Sociales, X (№ 620).

Capel, H. (25 de Octubre de 2003). Quo vadis Geographia? La geografía española y los concursos para la habilitación del profesorado universitario. Biblio 3W. Revista Bibliográfica de Geografía y Ciencias Sociales, VIII (№ 469).

Carlos, A. F. (1 de Agosto de 2007). A "Geografia Crítica" e a crítica da Geografia. Scripta Nova. Revista Electrónica de Geografía y Ciencias Sociales , vol. XI (245 (3)).

Casella, D. M. (16 de Novembro de 2007). A crise ambiental: uma análise jus-sociológica. Acesso em 11 de Dezembro de 2013, disponível em Webartigos: http://www.webartigos .com/artigos/acrise-ambiental/2726/.

Cauvin, C. (2002, January 15). Cognitive and cartographic representations : towards a comprehensive approach. Cybergeo : European Journal of Geography [on line], Cartographie, Imagerie, SIG , 206 . CNRS-UMR.

Chandler, C., Olson, R., Deroy, S., \& Brodeick, K. (2006, Abril). PGIS as a sustained (andsustainable?) practice:First Nation experiences inTreaty 8 BC, Canada. Participatory Learning and Action , 54, pp. 51-57.

Chapin, M., Lamb, Z., \& Threlkeld, B. (2005). Mapping Indigenous Lands. Annual Review of Anthropology, Volume 34.

Chuvieco, E., BOSQUE SENDRA, j., PONS, X., CONESA, C., SANTOS, J. M., GUTIÉRREZ PUEBLA, J., et al. (2005). ¿Son las tecnologías de la Información Geográfica (TIG) parte del núcleo de la Geografía? Boletín de la Asociación Española de Geógrafos , 40, pp. 35 - 55. 
Crang, M., \& Thrift, N. J. (2000). Thinking Space (Volume 9 Critical geographies ed.). Psychology Press.

Dagognet, F. (1977). Une épistémologie de l'espace concret: néo-géographie (Vol. Volume 33 de Problèmes et controverses). J. Vrin.

Denzin, N. K., \& Lincoln, Y. S. (1994). Handbook of qualitative research. Sage Publications.

Dobson, J. (1993). The Geographic Revolution: A Retrospective on the Age of Automated Geography. The Professional Geographer , 45 (4), pp. 431-439.

Ducrot, R., Camargo, M., \& Jacobi, P. (2004). O uso dos jogos de papéis, como ferramenta de Educacião ambiental, facilitando a negociação dos recursos hídricos. WEEC- World Environmental Education Congress. Anais, 2. Rio de Janeiro.

Fabrikant, S. I. (2001). Evaluating the usability of the scale metaphor for querying semantic spaces. Foundations of Geographic Information Science International Conference Proceedings. , 2205, pp. 156-172.

Ferreira, M. C. (2006). Considerações Teórico-metodológicas sobre as origens e a inserção do Sistema de Informação Geográfica na Geografia. In: A. Vitti, Contribuições à história e à epistemologia da Geografia (Primera ed., pp. 101-125). Rio de Janeiro: Bertrand Brasil.

García Ballesteros, A. (1998). Métodos y técnicas cualitativas en geografía social. Barcelona: OikosTau.

Gauthier, G., Reed, A., Berteaux, D., Giroux, J.-F., Rochefort, L., Bêty, J., et al. (1988). Ecological Studies and Environmental Monitoring at Bylot Island Sirmilik National Park. ECOLOGICAL STUDIES AND ENVIRONMENTAL MONITORING PROJECT - ANNUAL PROGRESS REPORTS .

Giddens, A. (1995). Politics, Sociology and Social Theory: Encounters with Classical and Contemporary Social Thought. Stanford University Press.

Goodchild, M. (2009, June 2009). NeoGeography and the nature of geographic expertise. Journal of Location Based Services, Vol. 3 (No. 2), pp. 82-96. 
Hackitectura. (2009). I Encuentro Internacional de Cartografía Ciudadana. Gijón: Centro de Arte y Creación Industrial.

Hagget, P. (1972). Geography : A Modern Synthesis. London: Harper \& Row Limited.

Hammersley, M. (1992). What's Wrong with Ethnography?: Methodological Explorations. Psychology Press.

Herlihy, P. H., \& Knapp, G. (2003). Maps of, by, and for the Peoples of Latin America. Human Organization, 62 (4) ): 303.

Hiernaux, ,. D., \& Lindon, A. (2006). Tratado de Geografía Humana. Capíitulo 4. Geografía Urbana: Una mirada desde America Latina. Iztapalapa. México. (Primera Edición ed.). Barcelona: Anthropos Editorial. Universidad Autónoma Metropolitana.

Kuhn, T. S. (1970). The Structure of the Scientific Revolutions (2nd ed., enl ed.). Chicago: The University of Chicago Press.

Lefebvre, H. (2000). La production de l'espace (éd. 4a ed. ). Paris: Anthopos.

Lévy, J. (1999). Le tournant géographique: penser l'espace pour lire le monde. Paris: Belin.

Lévy, J., \& Lussault, M. (2003). Dictionnaire de la géographie et de l'espace des sociétés. Paris: Belin.

Luntley, M. (2003). Wittgenstein: Meaning and Judgement. London: Wiley-Blackwell.

Lynch, K. (1960). The Image of the City. Boston: MIT Press.

Martín, J. C. (1999). Nuevas realidades en el desarrollo local en España e Iberoamérica. Actas del Seminario Internacional sobre perspectivas de desarrollo en Iberoamerica (pág. 743). Santiago de Compostela: Servicio de Publicaciones e Intercambio Cientifico.

Martin, R. L. (2000). Editorial: In memory of maps. Transactions of the Institute of British Geographers (n.25), pp. 3-5. 
Mc Master, R. B., \& McMaster, S. (2002, January). A History of Twentieth-Century American Academic Cartography. Cartography and Geographic Information Science, Vol. 29 (No. 3), pp. 305321.

McCall, M. K., \& Minang, P. A. (2005). Assessing Participatory GIS for Community-Based Natural Resource Management: Claiming Community Forests in Cameroon. Geographical Journal , 171 (4), pp. 340-358.

McHarg, I. (1969). Design with nature. Garden City, N.Y.: Published for the American Museum of Natural History [by] the Natural History Press.

Morato, R. G. (25 de Novembro de 2008). Análise espacial e desigualdade ambiental no Município de São Paulo. Tese de Doutorado . São Paulo, São Paulo, Brasil: Universidade de São Paulo.

Morato, R. G., Kawakubo, F. S., \& Luchiari, A. (Julho de 2003). Mapeamento da Qualidade de Vida em Áreas Urbanas: conceitos e metodologias. Revista Terra Livre , 2 (21), pp. 241-248.

Muehrcke, P. C., \& Muehrcke, J. O. (1986). Map use: Reading, Analysis, and Interpretation (Second Edition ed.). Madison: JP Publications.

Openshaw, S. (1991). Developing Appropiate Spatial Analysis Methods for GIS. In D. Maguire, M. Goodchild, \& D. Rhind, Geographical Information Systems: Principles and Applications (Second Edition ed., pp. 389-342). London: Wiley.

Papadimitriou, F. (2010). Neo-Geografias, Notopia, Mapas Culturais e GIS da Próxima Geração. $3^{\circ}$ Simpósio Iberoamericano de História da Cartografia - SIAHC (p. 10). São Paulo: Faculdade de Filosofia, Letras e Ciências Humanas.

Patton, M. Q. (1990). Qualitative Evaluation and Research Methods, (Second ed.). Sage.

Pedone, C. (1 de Febrero de 2000). El trabajo de campo y los métodos cualitativos. Necesidad de nuevas reflexiones desde las geografías latinoamericanas. Scripta Nova. Revista Electrónica de Geografía y Ciencias Sociales (№ 57). 
Pérez Machado, R. P. (15 de Enero de 2009). Nuevas tecnologías en la geografía contemporánea: consideraciones sobre un debate español. Biblio 3w: Revista Bibliográfica de Geografía y Ciencias Sociales. Serie Documental de Geocrítica. Vol. 14. Barcelona. , Vol. XIV (№ 809).

Pérez Machado, R. P., \& Candeau Dufat, R. V. (2008). Los mapas inexactos y el reto para los Sistemas de Información Geográfica. Resumenes. Coloquio Internacional Los Giros de la Geografía Humana: Desafios y Horizontes. Ciudad de México: Universidad Autónoma Metropolitana.

Perkins, C. (2004). Cartography: cultures of mapping: power in practice. Progress in Human Geography , 28 ( n. 3), pp. 381-391.

Philip, L. J. (1998). Combining quantitative and qualitative approaches to social research in human geography-an impossible mixture? Environment and Planning , A (30 (2)), pp. $\quad 261$ - 276.

Presotto, A. (2009). Mapas cognitivos de primatas: análise de movimentos e rotas de Cebus nigritus apoiada por sistemas de informação geográfica. Universidade de São Paulo, Departamento de Geografia. São Paulo: Faculdade de Filosofia, Letras e Ciências Humanas. .

Quintero, S. (2006). Capitulo 23: Geografía y Cartografía. En D. Hiernaux, \& A. Lindón, Tratado de Geografía Humana. (Primera Edición ed., págs. 557-581). Barcelona: Anthropos Editorial. Universidad Autónoma Metropolitana.

Salitchev, K. A. (1979). Cartografia (Primeira Edición ed., Vol. Único). La Habana: Editorial Pueblo y Educación.

Santos, M. (2002). Por uma Geografia Nova (Vol. Coleção Milton Santos; 2). São Paulo: EDUSP.

Santos, M. (2000). Por uma outra Globalização (5 ed.). São Paulo: Record.

Sauer, C. O. (1927). Geography of Pennyroyal. A study of the Influence of Geology and Physiography upon the Industry, Commerce and Life of the People (First Edition ed.). Frankfort, Kentucky, USA: The State Journal Company.

Sauer, C. O. (1925). The Morphology of Landscape (First Edition ed., Vol. II). Berkeley, California, USA: University of California Press. 
Sauer, C. O. (1963). The Morphology of Landscape. In J. Leighly, Land and Life: A Selection from the writings of Carl Ortwin Sauer (pp. 315-350). Berkeley: University of California Press.

Slocum, T. (1990). The use of quantitative methods in major geographical journals, 1956-1983. The Professional Geographer. Forum and Journal of the Association of American Geographers (42 (1)), pp. 84-94.

Soja, E. W. (1990, Dec.). Postmodern Geographies: The Reassertion of Space in Critical Social Theory. Annals of the Association of American Geographers, Vol. 80 (No. 4), pp. 649-654.

Strauss, A. L. (1987). Qualitative Analysis for Social Scientists. Cambridge: Cambridge University Press.

Tapiador, F. J. (20 de Agosto de 2004). Wittgenstein y la geografía cuantitativa contemporánea. Biblio 3W, Revista Bibliográfica de Geografía y Ciencias Sociales , IX (№ 529).

Taylor, S. J., \& Bogdan, R. (1984). Introduction to qualitative research methods: the search for meanings. Wiley.

Thrift, N. J. (1996). Spatial Formations. SAGE Publications.

Tomlin, C. D. (1990). Geographic information systems and cartographic modeling. Prentice Hall.

Tuan, Y.-F. (1974). Topophilia: A Study of Environmental Perception, Attitudes, and Values (Vol. Columbia University Press). New York.

Winchester, H. (1996). Ethical Issues in Interviewing as a Research Method in Human Geography. Australian Geographer , 2 (№1), pp. 117-131. 